\title{
Applications and validation of immunoassays for pesticides analysis
}

\author{
M.-C. Hennion
}

École Supérieure de Physique et Chimie Industrielles de Paris (ESPCI), Laboratoire Environnement et Chimie Analytique (ERS CNRS 657), 10 rue Vauquelin, 75231 Paris Cedex 05, France

Immunoassay techniques provide a simple, powerful and inexpensive method for pesticide analysis which has been widely used in monitoring programs especially in the US. Their rapid and recent development witnesses of their increasing acceptance and is the result from the demonstration of quality and validity compared to more traditional techniques.

\footnotetext{
T
}

he time and expense involved in classical analytical methods (i.e., sampling, sample preparation, and laboratory analysis) limit the number of samples that can be analyzed in environmental surveys. There is a real need for developing fast, easy to use, robust, sensitive, cost-effective and field-analytical techniques. Immunoassays (IAs) meet these requirements and many pesticides can be analyzed and monitored at regulatory levels without any sample preparation method. They are increasingly used and a few IAs have been recently accepted as screening methods by the US EPA and one for the total determination of triazines.

Current research includes the development of new assay formats, multi-residue assays, and flow-injection immunoassays. An evaluation of the performances of commercially available IAs for pesticides analysis as well as a selection of recent applications in monitoring programs are presented here. 


\section{Characteristic of immunoassays for pesticides}

IAs involve the use of antibodies characterized by specific structural recognition which enables highly specific interactions with the homologous antigen, usually the target analyte. The characteristics of some commercially available IAs for pesticides analysis are reported in table I. Pesticides are numerous and many laboratory-made IAs for other target pesticides have been developed as reported in the literature in recent reviews [1-11]. Thanks to the efforts made by regulatory agencies and manufacturers, information is now available on data interpretation, on quality assurance, and on quality control to improve the reliability of IAs. Data reported in table I are provided by manufacturers and therefore can help for the selection of an appropriate IA. However, even if the method appears simple, some knowledge of the fundamentals of the method is necessary in making a good use of an IA, and especially in understanding why some IAs are highly selective and sensitive for some target pesticides whereas other cannot, and also, why some can be used as a quantitative analytical method whereas others only as a screening technique.

The basic principle of an IA involves the antigen-antibody reaction. In most IA formats for pesticide analysis, the antibodies are immobilized on a solid support and the measurement of the sites bound by the antigens is made because the antibody occupancy reflects the concentration of analytes in the medium. However, since the binding reaction does not produce a signal, a tracer should be added which allows one to estimate the occupancy by measuring the tracer signal. The labels capable of detecting the immunological reaction with the purpose of giving quantitative measurements can be fluorescent, chemiluminescent, enzymes or radioisotopes.

\section{Description of an ELISA sequence}

Most of the commercial IAs for pesticides are enzymelinked immunosorbent assays (ELISAs) used in the competitive configuration indicated in figure 1.

Two formats are available and differ only in the solid surface used for the immobilization. One format uses antibodycoated tubes or wells (i.e., Millipore, ImmunoSystem, Ensys, Quantix and most laboratory-made IAs). The other one consists of antibodies covalently bound to $1 \mu \mathrm{m}$ magnetic particles which act as the solid support (Ohmicron systems). Typical sample volumes are $100-250 \mu \mathrm{L}$. According to the law of mass action, the more analyte there is in the sample, the more enzyme conjugate it will displace from the binding sites and the original analyte concentration in the sample can be determined by measuring the amount of enzyme conjugate bound to the antibodies. Quantification requires that unbound (or free) conjugates and antigens have been removed from the solution. For antibody coated to tubes or wells, this step is simply performed by washing the tube or well. When using magnetic particles, the test tube is placed in a magnetic field which pulls the magnetic particles to the bottom of the test tube and a washing allows the separation of bound analytes and conjugates from unbound ones. Then, the amount of enzyme conjugates bound to the antibodies is measured by adding a substrate and a chromogen to detect the enzymes. The color produced is proportional to the
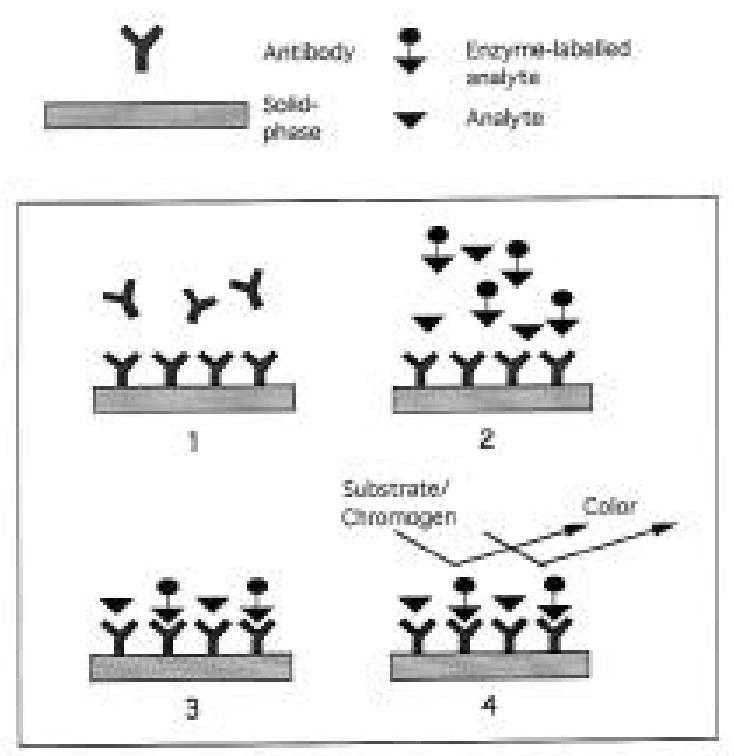

Figure 1. Sequence of an ELISA test. 1) immobilization of a known amount of antibodies to a solid-phase; 2) competition between the pesticide molecules in the sample and a known amount of enzyme conjugates for a limited number of binding sites; 3) after incubation, separation of the bound enzyme conjugates and /or pesticides from the free ones; 4) addition of the substrate and chromogen, incubation during a certain time, and addition of a stopping reagent. From reference [11].

amount of bound enzyme conjugates and therefore inversely proportional to the amount of analytes present in the sample. A darker color means less analytes in the sample whereas a light color indicates a high concentration of analytes in the sample.

\section{Quantification via the dose-response curve}

Quantitative measurements can be obtained by measuring the absorbance of standard samples having known concentrations using a spectrophotometer. When response is plotted versus the logarithm of the analyte concentration (see Fig. 2), the curve has a sigmoïdal shape with a relatively linear portion around the point of half inhibition $\left(\mathrm{IC}_{50}\right)$.

The working range of the calibration curve is defined by the lower and upper limits that can be exploited. To allow direct comparison of several standard curves, the absorbance data are normalized between $100 \%$, which corresponds to the absorption of a zero control $\left(A_{0}\right)$ and $0 \%$ which corresponds to the absorbance of a standard excess $\left(A_{\text {excess }}\right)$. The transformation is performed according to $\% B / B_{0}$ equal to $100\left(A-A_{\text {excess }}\right) /\left(A_{0}-A_{\text {excess }}\right)$. Various mathematical transformations have been proposed for linearization of the standard curves [12]. The most used transform concerns the normalized response, and is defined by the logit $B / B_{0}$ equation, equal to $\log \left(B / B_{0}\right) /\left(1-B / B_{0}\right)$. This logit transform attempts to add the tailed regions of the sigmoïdal curve into the linear transform. However, one has to take note that the scale on the $y$ axis is no longer linear, since the logit transform compresses the response in the middle of the curve and expands the low and high ends of the curve. 
Table I. Main characteristics of some commercial immunoassays (ELISAs) for pesticide analysis in aqueous matrices (from data included in various documents distributed by J.T. Baker, Ohmicron and Millipore). Format, W= Ab-coated 96-well plate, $M=$ Ab-bounded magnetic particles. $\left(^{*}\right)$ : cross-reactivities are given for the compounds showing LDD and $I_{50}$ values in the working range. The exact corresponding values can be found in the documents. Not all the reported data given by the supplier are given and no reported cross-reactivity (ncr) means that identified cross-reactivity are out of the linear range.

\begin{tabular}{|c|c|c|c|c|c|}
\hline Analyte & Format & $\begin{array}{l}\text { Quantification } \\
\text { range }(\mu g / L)\end{array}$ & $L D D(\mu g / L)$ & $\begin{array}{l}I C_{50} \\
(\mu g / L)\end{array}$ & $\begin{array}{l}\text { Main cross-reactivity } \\
\text { compound * }\end{array}$ \\
\hline $2,4-D$ & W & $0.5-100$ & 0.1 & 2.3 & 2,4-D alkyl esters. \\
\hline $2,4-D$ & M & $0.7-50$ & 0.7 & 15 & 2-4-D alkyl esters. \\
\hline $\begin{array}{l}\text { Acetanilide } \\
\text { (acetochlor) }\end{array}$ & W & $0.1-5$ & 0.02 & 1.5 & $\begin{array}{c}\text { Acetochlor; Alachlor; Butachlor; Furalax; } \\
\text { Metalaxyl; Metolachlor. }\end{array}$ \\
\hline Alachlor & W & $0.1-2.5$ & 0.046 & 0.6 & Alachlor sulfonic acid. \\
\hline Alachlor & M & $0.05-5$ & 0.05 & 0.98 & Alachlor ESA. \\
\hline Aldicarb & W & $1-$ & 0.4 & 5 & Aldicarb sulfone. \\
\hline Aldicarb & M & $0.25-100$ & 0.25 & 9.28 & Aldicarb sulfone; Aldicarb-sulfoxide. \\
\hline Atrazine & & & & & \\
\hline (High sensitivity) & M & $0.015-1$ & 0.015 & 0.22 & Propazine; DEA. \\
\hline Atrazine & M & $0.05-5$ & 0.046 & 0.72 & $\begin{array}{c}\text { Propazine; Ametryn; Prometryn ; Prometon; } \\
\text { DEA; Simazine; Terbutylazine. }\end{array}$ \\
\hline Benomyl/ & & & & & \\
\hline $\begin{array}{l}\text { Carbendazim } \\
\text { Benomyl/ }\end{array}$ & W & $0.4-10$ & 0.1 & 2 & Thiophanate; Thiophanate methyl. \\
\hline Carbendazim & M & $0.1-5$ & 0.1 & 1.6 & Benomyl. \\
\hline Captan & M & $10-3000$ & 10 & 420 & Captafol. \\
\hline Carbaryl & M & $0.25-5$ & 0.25 & 2.57 & ncr. \\
\hline Carbofuran & M & $0.06-5$ & 0.056 & 0.815 & metabolites. \\
\hline Chlorothalonil & M & $0.07-5$ & 0.07 & 1.12 & Pentachloronitrobenzene; hexachlorobenzene. \\
\hline Chlorpyrifos & W & $0.1-1$ & 0.1 & 0.3 & Chlorpyriphos methyl; Fenchlorphos. \\
\hline Chlorpyrifos & M & $0.1-3$ & 0.1 & 0.94 & Diazinon; Chlorpyriphos-methyl. \\
\hline Chlorsulfuron & W & $0.04-0.8$ & 0.04 & 0.22 & ncr. \\
\hline Cyanazine & W & $0.25-$ & 0.14 & 0.73 & ncr. \\
\hline Cyanazine & M & $0.04-3$ & 0.035 & 0.43 & Terbutylazine. \\
\hline Diazinon & W & $0.03-0.5$ & 0.002 & 0.1 & Diazoxon. \\
\hline Imazapyr & W & $0.3-30$ & 0.3 & 3 & Imazethapyr. \\
\hline Isoproturon & W & $0.05-0.5$ & 0.02 & 0.13 & ncr. \\
\hline Metalaxyl & W & $0.1-25$ & 0.1 & 0.3 & Fluralaxyl. \\
\hline Methomyl & M & $0.45-15$ & 0.45 & 4.15 & Thiodicarb. \\
\hline Metolachlor & W & $0.1-2$ & 0.1 & 0.53 & ncr. \\
\hline Metolachlor & M & $0.05-5$ & 0.05 & 0.85 & Acetochlor; Metalaxyl; Butachlor. \\
\hline Metribuzin & M & $0.1-3$ & 0.05 & 0.5 & no data. \\
\hline Metsulfuron & W & $0.025-0.5$ & 0.020 & 0.1 & Thifensulfuron; Sulfuron-methyl; Triasulfuron. \\
\hline Paraquat & W & $0.025-0.2$ & 0.017 & 0.079 & Diquat. \\
\hline Paraquat & M & $0.20-0.5$ & 0.020 & 0.30 & $\begin{array}{c}\text { Methylbipyridinyl methyl sulfonium salt; } \\
\text { Diethyl paraquat }\end{array}$ \\
\hline $\begin{array}{l}\text { Parathion } \\
\text { (methyl) }\end{array}$ & W & $0.04-0.4$ & 0.03 & 0.3 & Parathion-ethyl. \\
\hline Procymidone & M & $0.8-100$ & 0.8 & 19 & ncr. \\
\hline Silvex & M & $5-250$ & 1.4 & 58 & Silvex isooctyl ester; Silvex methyl ester; $2,4,5,-\mathrm{T}$. \\
\hline Thiabendazole & W & $0.25-4$ & 0.25 & & no data. \\
\hline Triasulfuron & W & $0.05-1$ & 0.04 & 0.36 & Metsulfuron methyl. \\
\hline Triazine & W & $0.05-20$ & 0.05 & 0.25 & $\begin{array}{l}\text { Ametryn; Propazine; DEA; Prometon; } \\
\text { Prometryn; Simetryn ; Simazine. }\end{array}$ \\
\hline $\begin{array}{l}\text { Triazine } \\
\text { (high sensitivity) }\end{array}$ & W & $0.01-0.5$ & 0.01 & 0.080 & Prometon; Simetryn; Propazine; DEA; Simazine. \\
\hline Trichlorpyr & M & $0.1-3$ & 0.03 & 0.78 & 2-Methoxy-3,5,6-trichlorpyridine. \\
\hline Trichlor-pyrindinol & M & $0.25-6$ & 0.25 & 2.31 & nor. \\
\hline $\begin{array}{l}\text { Urea herbicides } \\
\text { (Chlortoluron) }\end{array}$ & W & $0.05-2$ & 0.04 & 0.53 & Neburon; Diuron; Chlorbromuron; Linuron; Monuron. \\
\hline
\end{tabular}




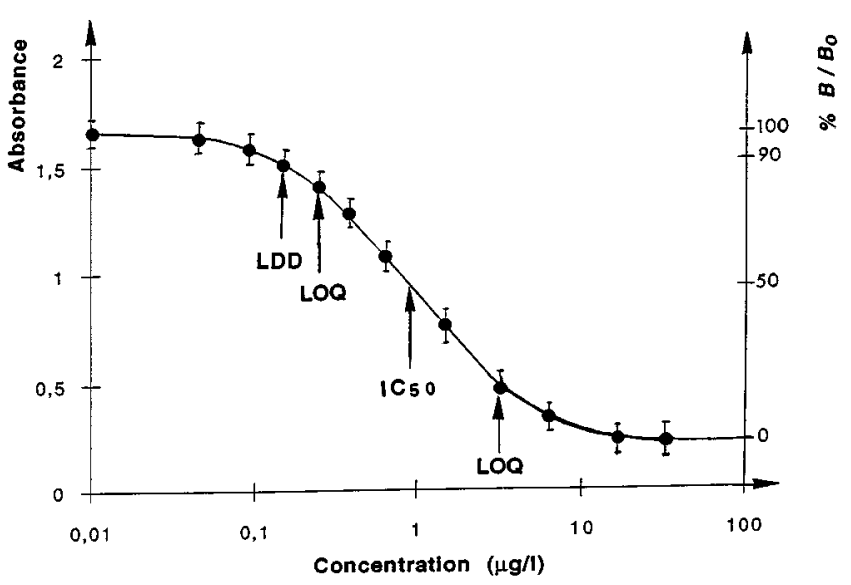

Figure 2. Typical sigmoidal dose-response curve obtained by measuring the absorbance of the solution after incubation with a fixed concentration of antibodies and enzyme conjugates, with increasing concentration of antigen. Definition of usual parameters: limit of detection or least detectable dose (LDD), lower and upper limit of quantification (LOQ), inhibition concentration at $50 \%\left(\mathrm{IC}_{50}\right) . A_{0}$ and $A_{\text {excess }}$ are the absorbances of the zero-control solution and of the standard excess solution. From reference [11].

In most of the ELISAs for pesticides, the working range is obtained for about two log units, as can be seen in table I. For the majority of the commercial and laboratory ELISAs the lower limits of the working range are at concentration levels $0.02-0.1 \mu \mathrm{g} / \mathrm{L}$ and the upper limits at $5-10 \mu \mathrm{g} / \mathrm{L}$. They therefore easily meet the EU requirements for drinking-water regulatory control without requiring a concentration step.

The limit of detection, or least detectable dose (LDD) is the smallest concentration of the analyte that produces a signal significantly different from zero with a stated degree of confidence. There is a general consensus in favor of selecting the dose which inhibits $10 \%$ of the binding of the antibody with the enzyme tracer at $90 \% B / B_{0}$, or the dose providing two or three times the standard deviation from the mean measurement of the blank dose signal. The LDD is then often measured using the standard samples in pure water or buffer. Table I shows that several assays have LDD below $50 \mathrm{ng} / \mathrm{L}$.

The limit of quantification (LOQ) is the level above which quantitative results can be obtained with a stated relative precision, or specified degree of confidence, in real samples [12]. In some cases, the LDD value at $90 \% B / B_{0}$ is not in the linear range of the dose-response curve, and the selected LOQ is defined by the upper limits of the linear range of the dose-response curve.

The precision of an IA is defined as the extent to which replicate analyses of a sample agree with each other. According to the non-linear shape of the dose-response curve, the variance is non-uniform, and the experimental errors increase towards the two limits of the measuring range, -especially in the non-linear parts. Therefore, the precision should be given by calculating the standard deviation per percent of the coefficient of variation versus concentration. The highest precision is obtained for concentration lev- els close to $\mathrm{IC}_{50}$. This concentration is often given as the characteristic of a test (see Tab. I) so that one can estimate the best range for quantitative measurements.

\section{Specificity and cross-reactivity of ELISAs}

Antibodies (Abs) are the critical part of all IAs, since their quality g reatly contributes to their sensitivity and specificity [9]. However, besides their specificity, antibodies are also known for their cross-reactivity, i.e., the extent to which they react with compounds structurally related to the analyte, or sometimes with entirely different compounds. The degree of cross-reactivity depends on both the pesticide molecule and on the way in which the antibodies are created. As the target molecule becomes smaller, the number of determinant groups in the molecule decreases and the probability of cross-reactivity increases.

The technology for developing specific antibodies is an active area, sometimes using very sophisticated methods. Up to now, the commercial IAs are using mainly polyclonal and monoclonal antibodies. Polyclonal antibodies have some limitations because polyclonal antiserum can vary from one animal to another and their supply ends when the animal dies. These problems are solved commercially by using serum pools that are carefully characterized. A constant supply of identical antisera can be provided by the hybridoma technique which generates unlimited amounts of homogeneous monoclonal antibodies with constant affinities and cross-reactivities [2,13].

\section{Experimental measurement of the cross-reactivity}

Reliable quantitative determinations using the calibration curve can be obtained provided there is no cross-reactivity. Experimental measurement of the extent of cross-reactivity is performed by spiking water with related compounds, recording the corresponding absorbance, and drawing the corresponding dose-response curves, similar to the standard curves. The percent of cross-reactivity (\% CR) is usually defined as 100 -fold the ratio between the $\mathrm{IC}_{50}$ values of the antigen and of the cross-reactant. Instead of giving the $\%$ cross-reactivity at $50 \% \mathrm{~B} / \mathrm{B}_{0}$, named $\mathrm{CR}_{50}$, one can find the $\mathrm{IC}_{50}$ values for both the target analyte and the cross-reacting components. However, the $\mathrm{CR}_{50}$ values (or the $\mathrm{IC}_{50}$ values) are not always sufficient to estimate the cross-reactivity because the displacement curves of cross-reactants may not be parallel to the standard curve over the whole working range. Therefore the LDD values at $90 \% B / B_{0}$ are given, in addition to $\mathrm{IC}_{50}$ values, by companies as characteristics of ELISAs. Table II gives an example of the information provided for the characterization of the specificity of an atrazine ELISA.

Cross-reactivity is particularly visible for prometon which shows a LDD value of $0.056 \mu \mathrm{g} / \mathrm{L}$, close to that of atrazine $(0.046 \mu \mathrm{g} / \mathrm{L})$, whereas the $\mathrm{IC}_{50}$ are respectively 2.22 and $0.72 \mu \mathrm{g} / \mathrm{L}$, so that cross-reactivity is higher near the LDD value $\left(\mathrm{CR}_{90} 82 \%\right)$ than it is at $50 \% B / B_{0}\left(\mathrm{CR}_{50} 32 \%\right)$. Any practitioner can then rapidly estimate the cross-reactivity from data provided with ELISA kits and selection can be made according to the target analytes and transformation products. For example, table I shows that ELISA kits other 
than that described in table II are available for atrazine. The high-sensitivity magnetic-particle-based IA shows crossreactivity with propazine and with de-ethylatrazine, whereas the microtitre plates have a low cross-reactivity for de-ethylatrazine. Depending on whether or not the de-ethylatrazine should be included in the survey, one can thus better select the ELISA kit.

Data from atrazine kits are always given as examples of cross-reactivity, but, most of the ELISA kits designed for compounds other than atrazine are more specific. A list of cross-reacting compounds, classified in order of increasing cross-reactivity is given in table I. Many ELISAs show few or no cross-reactivity effects, and can be used for single component analysis. Class-selective IAs are available mainly for triazine and phenylurea herbicides.

\section{Relationship with cross-reactivity and antibody characteristics}

The numerous studies of immunoassays made specifically for atrazine or its metabolites have pointed out the relationship between the antibodies and the cross-reactivity of the immunoassay [14-20]. The specificity of the IAs is not always much higher when using monoclonal instead of polyclonal antibodies. Especially when polyclonal antibodies show high cross-reactivity, it is likely that the monoclonal ones will also show some cross-reactivity. The difficulty of making a very specific atrazine antibody results mainly from the closely related structures of several compounds within the triazine group, because many other chlorotriazines have two common determinants with atrazine. Highly specific ELISAs have been made with monoclonal antibodies for terbutylazine [21] or with polyclonal antibodies for cyanazine [22], but both terbutylazine and cyanazine have determinants which are less common with other triazines.

\section{Matrix effects in environmental samples}

The range of detection levels of pesticides found in real water samples implies their analysis without any sample pretreatment in most cases. Therefore it is important first to know whether the calibration curves constructed with standard solutions can be used with real samples.

The matrix effect can be investigated by constructing dose-response curves with real samples spiked within the working range, and including a blank run, or by measuring the recoveries for real samples spiked at known levels, using the standard curve constructed with the standard solutions provided within the kit. Using an IA for carbaryl analysis, no significant differences in slope and $\mathrm{IC}_{50}$ were observed when running the carbaryl ELISA in river-, tap- or well water compared with the standard curve obtained for the experiment carried out in buffer [23]. In general, the recoveries measured with spiked surface water samples indicate few matrix effects. As an example, 326 drinking-, surface-, and ground-water samples obtained throughout the USA were fortified with $1.5 \mu \mathrm{g} / \mathrm{L}$ of metalochlor to evaluate the sample matrix effect [24]. The metalochlor concentrations of the water samples ranged from less than 0.04 up to $4.54 \mu \mathrm{g} / \mathrm{L}$ before they were spiked. The experimental recoveries ranged between 76 and $120 \%$, with a mean recovery of $96 \%(\mathrm{SD}=9 \%)$.
Table II. Specificity of an atrazine ELISA for various triazine analogues (Atrazine RaPID assay), expressed respectively as the least detectable dose (LDD) which is estimated at $90 \% B / B_{0}$, or as the dose required for $50 \%$ absorbance inhibition $\left(50 \% B / B_{0}\right) ; C_{90}$ and $C_{50}$ have been obtained as the simple ratios of values for crossreacting compounds and of atrazine values.

\begin{tabular}{lcccc} 
Compounds & $\begin{array}{c}L D D \\
(\mu g / L)\end{array}$ & $\begin{array}{c}I C_{50} \\
(\mu g / L)\end{array}$ & $\begin{array}{c}C R_{90} \\
(\%)\end{array}$ & $\begin{array}{c}C R_{50} \\
(\%)\end{array}$ \\
\hline Atrazine & $\mathbf{0 . 0 4 6}$ & $\mathbf{0 . 7 2}$ & $\mathbf{1 0 0}$ & $\mathbf{1 0 0}$ \\
Propazine & 0.033 & 0.74 & 139 & 97 \\
Ametryn & 0.053 & 0.39 & 87 & 184 \\
Prometryn & 0.054 & 0.64 & 85 & 112 \\
Prometon & 0.056 & 2.22 & 82 & 32 \\
De-ethylatrazine & 0.062 & 3.21 & 74 & 22 \\
Terbutryn & 0.090 & 5.50 & 54 & 13 \\
Terbutylazine & 0.310 & 15.5 & 15 & 5 \\
Simazine & 0.340 & 4.90 & 13 & 15 \\
De-isopropylatrazine & 0.800 & 217 & 6 & 0.3 \\
Cyanazine & 1.0 & $>10000$ & 5 & - \\
2-Hydroxyatrazine & 1.1 & 148 & 4 & 0.5 \\
\hline
\end{tabular}

Oubina et al. [25,26] have shown that the matrix of estuarine water did not affect the standard curve in the chlorpyriphos-ethyl assay. Estuarine water have also been analyzed for atrazine and alachlor using ELISAs: no effect was observed for alachlor, but some reduction in response was observed for atrazine [26-29].

The effect of the humic acid content of samples is often studied by spiking samples with a known amount of humic acids. The addition of humic acids up to $50 \mathrm{mg} / \mathrm{L}$ caused no interference from the samples for the ELISA determination of carbofuran in water [30].

The $\mathrm{pH}$ of natural waters does not usually affect the immunoassays. No difference in the chlorpyriphos determination was observed when samples were at $\mathrm{pH} 4$ or at $\mathrm{pH} 8$ [25].

\section{Application to environmental monitoring: Data interpretation and validation studies}

One must be aware that IAs do not measure the concentration of an analyte but that of indicator species giving absorbance in a colored solution. For an unknown sample, the sample response is compared to standard responses obtained with calibrators made of solutions spiked with the analyte-antigen. Therefore, a certain amount of the "analyteantigen" or an "equivalent of the analyte-antigen" is measured in the sample.

The validation of results given by IAs is usually performed by comparison with chromatographic methods. Environmental surveys provide a good opportunity [31]. When possible, validation of IAs is better performed using real samples contaminated by the analyte. This can even give an opportunity for identifying new cross-reactants and 
metabolites, as was the case for alachlor. The ethanesulfonic acid (ESA) metabolite was identified in real samples as a result of the frequency of false positives which were observed by using the ELISA screening kits for alachlor [32,33]. ELISA kits for the determination of carbofuran show no significant cross-reactivity towards the known metabolites. The correlation was correct $(r=0.967$, slope of 1.18) between ELISA measurements and LC methods which involved an extraction and a concentration step, a post-column derivatization, and fluorescence detection for ten naturally contaminated samples at concentrations within the $1-$ $4 \mu \mathrm{g} / \mathrm{L}$ range [30]. A good correlation was reported when studying 58 real samples contaminated by metalochlor (one of the most widely used herbicides in the US and Canada), as determined by an ELISA, with those from GC methods [24].

For pesticides which are less commonly detected in environmental water, validation studies are performed with spiked samples. Good correlations have been found using ELISA for the determination of chlorothanil as compared with GC-FID methods [34], and for carbendazim (or benomyl after transformation into carbendazim) as compared with LC determinations [35]. Oubina et al. [25] evaluated an ELISA for the determination of chlorpyrifos-ethyl and compared the results given by IA with those obtained by automated on-line solid-phase extraction followed by LC-DAD in spiked estuarine waters in the range $0-4 \mu \mathrm{g} / \mathrm{L}$. Marco et al. [23] validated two immunoassay methods for the environmental monitoring of carbaryl and 1-naphthol in groundwater samples.

Most examples of the use of ELISAs, performed with non-spiked samples are devoted to atrazine, since this herbicide is found everywhere in the world and is, of course, included in most environmental surveys [20,31,36-43]. Thurman et al., plotted the "atrazine-equivalent" versus the concentration of atrazine obtained by GC-MS for 127 surface water samples using a microplate atrazine ELISA [31]. As the GC-MS indicated that cyanazine and de-ethylatrazine were frequently detected with trace-concentrations of simazine and propazine, the agreement between ELISA measurements and GC-MS was good, especially for atrazine concentrations lower than $5 \mu \mathrm{g} / \mathrm{L}$. Another example showing the good correlation between ELISA and chromatographic data corresponds to a survey of 750 water samples collected from four Vermont streams in the USA, with a set of 224 of them which have been also analyzed by GC-MS $[41,42]$. No false negative was observed and only $5.5 \%$ of the assays gave false positive using ELISAs.

\section{Sample pretreatment before ELISA measurements}

Methods for sample extraction prior to IA analysis have been discussed $[44,45]$. First, approaches that emphasize speed and minimal steps are desirable to keep costs down. For solid samples and complex matrices such as soil or foodstuffs, some sample preparation is generally needed. Classical extraction methods can be used. The extract is usually diluted before the ELISA measurement, so that the matrix effect is greatly reduced.
Usually, water samples are analyzed without sample pretreatment, since the typical environmental concentrations are in the range $0.1-10 \mu \mathrm{g} / \mathrm{L}$. Sample pretreatment is required when the expected concentrations are below or close to the limit of quantification, or when there is a strong matrix effect because of humic substances, for example. In that case, solid-phase extraction using disposable cartridges is well suited, the methanol desorption solution being diluted in buffer. Aga and Thurman [46] have applied such a pretreatment for the determination of atrazine in the range 2 $20 \mathrm{ng} / \mathrm{L}$ in surface water samples from six lakes in the Isles Royal National Park (Mi, USA) using SPE-ELISA and GCMS and Lucas et al. [47] analyzed 75 well-water samples for atrazine. They found a good correlation with the GC method, with only one false positive and no false negative using ELISA. They applied a rapid SPE sequence using a $\mathrm{C}_{18}$ cartridge (100 mL sample) in order to reduce the detection limits and to have data in the middle of the working range of their IAs. The coupling of SPE-ELISA was also applied to the simultaneous determination of alachlor and the ethanesulfonic acid (ESA) metabolite [38]. Alachlor and ESA were first isolated from water by SPE on a $\mathrm{C}_{18}$ cartridge and then eluted sequentially with ethyl acetate and methanol. Alachlor is soluble in ethyl acetate while the anionic ESA is not. Thus, ESA remains on the cartridge and is eluted later by methanol. The combination of SPE with ELISA effectively separates and quantifies both alachlor and ESA, using the same antibody for the two ELISA methods, with detection limits of $0.01 \mu \mathrm{g} / \mathrm{L}$ for alachlor and $0.05 \mu \mathrm{g} / \mathrm{L}$ for ESA.

\section{Quality assurance and guidelines for validation and use}

The acceptance of immunoassays is dependent upon the demonstration of quality and validity compared to more traditional methods. Confirmation of positive samples must be planned, according to the analytical requirements. If many samples are to be analyzed but only a few contaminated samples are expected, the use of ELISAs for screening with re-analysis of the positive samples by chromatographic methods may be a good use of IAs. The definition of "positive sample" may be different, depending on whether the survey is made for regulatory purposes or to study the transport or fate of a target pesticide. If many samples are likely to be contaminated, as in studies for field dissipation or for pesticide registration studies, the confirmation of positive detections will be expensive and diminish the advantages of using immunoassays. In such conditions, it is worthwhile having analytical conditions so that the ELISAs should be quantitative. An interesting field dissipation study was recently described for the disappearance of aerially applied fenitrothion in rice-crop waters in Spain [48]. For monitoring the fenitrothion residues in water, two different analytical techniques were used: an ELISA kit, and an automated on-line solid-phase extraction followed by liquid chromatography with diode-array detection or MS detection for unequivocal confirmation. Since there is no ELISA kit sensitive enough for measuring fenitrothion, the ELISA kit corresponded to parathion-ethyl. 


\section{Conclusion}

Immunoassay techniques provide a simple, powerful and inexpensive screening method with enormous potential, which includes the generation of quantitative data. They are gaining acceptance and the confidence of analytical chemists. They are competing successfully with traditional analytical methods because they are now evaluated by the same criteria according to well-defined quality-assurance plans. However, users must know and recognize their limitations. In particular, they must be aware of the data interpretation and know that, depending on the selected application, some immunoassays can be quantitative whereas some others cannot. The development of guidelines will promote consistent validation and data reporting and applications will certainly help the wider acceptance of this technology.

Effort are still to be made for developing immunoassays at least for the most common pesticides. One important limitation of the development of new immunoassays is the production of new antibodies. The future seems to indicate that this limitation will be overcome using recombinant antibodies from sufficiently large libraries. Flow injection immunoassays and dipstick formats will certainly be the "field format" of the near future.

\section{References}

1. Van Emmon, J.; Lopez Avila, V. Anal. Chem. 1992, 64, 79A.

2. Hock, B.; Giersch, T.; Kramer, K. Analusis 1992, 20, 29.

3. Sherry, J. P. Crit. Rev. Anal. Chem. 1992, 23, 217.

4. Niessner, R. Anal. Methods Instrum. 1993, 1, 134.

5. Meulenberg, E. P.; Mulder, W. H.; Stoks, P. G. Environ. Sci. Technol. 1995, 29, 553.

6. Hammock, B. D.; Gee, S. J. In: Immunoanalysis of Agrochemicals, Emerging Technologies, Nelson, J. O.; Karu, A. E.; Wong, R. B. Eds., American Chemical Society, Washington, 1995; Vol. 586, p 2.

7. Van Emmon, J. M.; Gerlach, C. Environ. Sci. Technol. 1995, 29, 312A.

8. Marco, M. P.; Gee, S.; Hammock, B. D. Trends Anal. Chem. 1995, 14, 341 .

9. Marco, M. P.; Gee, S.; Hammock, B. D. Trends Anal. Chem. 1995, 14, 415.

10. Hennion, M. C.; Barceló, D. Anal. Chimica. Acta 1998 (in press).

11. Barceló, D.; Hennion, M. C. Immunochemical methods and biosensors, In: Trace determination of pesticides and their degradation products in water, Elsevier, Amsterdam, NL, 1997; pp 429-517.

12. Brady, J. F. In: Immunoanalysis of Agrochemicals, Emerging Technologies, Nelson, J. O.; Karu, A. E.; Won,g R. B. Eds., American Chemical Society, Washington, 1995; Vol. 586, p 287.

13. Hock, B.; Dankwardt, A.; Kramer, K.; Marx, A. Anal. Chim. Acta 1995, 311, 393.

14. Thurman, E. M.; Meyer, M.; Pomes, M.; Perry, C. A.; Schwab, A. P. Anal. Chem. 1990, 62, 2043.

15. Bushway, R. J.; Perkins, B.; Savage, S. A.; Lekousi, S. J.; Ferguson, B. S. Bull. Environ. Contam. Toxicol 1988, 40, 647.

16. Dunbar, B.; Riggle, B.; Niswender, G. J. Agric. Food Chem. 1990, 38, 433.

17. Gooddrow, M. H.; Harrison, R. O.; Hammock, B. D; J. Agric. Food Chem. 1990, 38, 990.

18. Wittman, C.; Hock, B. J. Agric. Food Chem. 1991, 39, 1194.
19. Muldoon, M. T.; Huang, R. N.; Hapeman, C. J.; Fries, G. F.; Man M. C., Nelson, J. O. J. Agric. Food Chem. 1994, 42, 747.

20. Schlaeppi, J. M.; Föry, W.; Ramsteiner, K. A; J. Agric. Food Chem. 1989, 37, 532.

21. Giersch, T.; Kramer, K.; Hock, B. Sci. Total Environ. 1993, 132, 435.

22. Lawruk, T. S.; Lachman, C. E.; Jordan, S. W.; Fleeker, J. R.; Herzog, D. P.; Rubio, F. M.; J. Agric. Food Chem. 1993, 41, 747.

23. Marco, M. P.; Chiron, S.; Gascon, J.; Hammock, B. D.; Barceló, D. Anal. Chim. Acta 1995, 311, 319.

24. Lawruk, T. S.; Lachman, C. E.; Jourdan, S. W.; Fleeker, J. R.; Herzog, D. P.; Rubio, F. M. J. Agric. Food. Chem. 1993, 41, 1426.

25. Oubina, A.; Ferrer, I.; Gascon, J.; Barceló, D. Environ. Sci. Technol. 1996, 30, 509.

26. Oubina, A.; Gascon, J.; Barceló, D. Environ. Sci. Technol. 1996, 30, 513.

27. Gascon, J.; Martinez, E.; Barceló, D. Anal. Chim. Acta 1995, $311,357$.

28. Lawruk, T. S.; Lachman, C. E.; Jourdan, S. C.; Fleeker, J. R.; Hayes, M. C.; Herzog, D. P.; Rubio, F. M. Environ. Sci. Technol. 1996, 30, 695.

29. Gascon, J.; Durand, G.; Barceló, D. Environ. Sci. Technol. 1995, 29, 1551.

30. Jourdan, S. W.; Scutellaro, A. M.; Fleeker, J. R.; Herzog, D. P.; Rubio, F. M. J. Agric. Food Chem. 1995, 43, 2784.

31. Thurman, E. M.; Goolsby, D. A.; Meyers, M. T.; Mills, M. S.; Pomes, M. L.; Kolpin, D. W. Environ. Sci. Technol. 1992, 6, 2440.

32. Baker, D. B.; Bushway, R. J.; Adams, S. A.; Macomber, C. S; Environ. Sci. Technol. 1993, 27, 562.

33. Macomber, C. S.; Bushway, R. J.; Perkins, L. B.; Baker, D. B.; Fan, T. S.; Ferguson, B. S. J. Agric. Food Chem. 1992, 40, 1450 .

34. Lawruk, T. S.; Gueco, A. M.; Jourdan, S. W.; Scutallero, A. M.; Fleeker, J. R.; Herzog, D. P.; Rubio, F. M. J. Agric. Food Chem. 1995, 43, 1413.

35. Itak,A.; Selisker, M. Y.; Jourdan, S. W.; Fleeker, J. R.; Herzog, D. P. J. Agric. Food Chem. 1993, 41, 2329.

36. Gascon, J.; Barceló, D. Chromatographia 1994, 38, 633.

37. Gascon, J.; Oubina, A.; Onnerfjord, P.; Ferrer, I.; Hammock, B. D.; Pilar-Marco, M. P.; Barceló, D. Anal. Chim. Acta 1996, $330,41$.

38. Aga, D. S.; Thurman, E. M.; Pomes, M. L. Anal. Chem. 1994, 66, 1495.

39. Kolpin, D. W.; Thurman, E. M.; Goolsby, D. A. Environ. Sci. Technol. 1996, 30, 335.

40. Thurman, E. M.; Goolsby, D. A.; Aga, D. S.; Pomes, M. L.; Meyers, M. T. Environ. Sci. Technol. 1996, 30, 569.

41. Gruessner, B.; Shambaugh, N. C.; Watzin, M. C. Environ. Sci. Technol. 1995, 29, 251.

42. Gruessner, B.; Shambaugh, N. C.; Watzin, M. C. Environ. Sci. Technol. 1995, 29, 2806.

43. Rubio, F. M.; Itak, J. A.; Scutellaro, A. M.; Selisker, M. Y.; Herzog, D. P. Food Agric. Immunol. 1991, 3, 113.

44. Lucas, A. D.; Gee, S. J.; Hammock, B. D. J. AOAC Int. 1995, 78, 585.

45. De Frutos, M. Trends Anal. Chem. 1995, 14, 133.

46. Aga, D. S.; Thurman, E. M. Anal. Chem. 1993, 65, 2894.

47. Lucas, A. D.; Schneider, P.; Harrison, R. O.; Seiber, J. N.; Hammock, B. D.; Biggar, J. W.; Rolston, D. E. Food Agric. Immunol. 1991, 3, 155.

48. Oubina, A.; Ferrer, I.; Gascon, J.; Barceló, D. Environ. Sci. Technol. 1996, 30, 3551. 